\section{Educational level and tuberculosis mortality in Colombia: growing inequalities and stagnation in reduction}

\author{
Nivel educacional y mortalidad por tuberculosis \\ en Colombia: crecientes inequidades y \\ estancamiento en su reducción
}

\author{
Nível de escolaridade e mortalidade por tuberculose \\ na Colômbia: desigualdades crescentes e \\ estagnação na redução da doença
}

\begin{abstract}
We aim to describe the role of educational inequalities, for sex and age groups, in adult tuberculosis (TB) mortality in Colombia, 1999-2017. We linked mortality data to data estimation of the national population based on censuses and surveys to obtain primary, secondary, and tertiary adult $(25+$ years of age) age-standardized mortality rates (ASMR) by educational level. Thus, a population-based study was conducted using national secondary mortality data between 1999 and 2017. Tuberculosis age-standardized mortality rates were calculated separately by educational level, sex, and age groups, using Poisson regression models. Educational relative inequalities in adult mortality were evaluated by calculating the rate ratio, and the relative index of inequality (RII). Trends and joinpoints were evaluated by annual percentage change (APC). We found that, out of the 19,720 TB deaths reported, 69\% occurred in men, and 45\% in older adults (men and women, aged 65+). Men presented higher TB mortality rates than women (ASMR men $=7.1 / 100,000$ inhabitants, ASMR women = 2.7/100,000 inhabitants). As mortality was consistently higher in the lowest educational level for both sexes and all age groups, inequalities in TB mortality were found to be high $(R I I=9.7$ and 13.4 among men and women, respectively) and growing at an annual rate of $8 \%$ and $1 \%$. High and increasing inequalities, regarding educational level, in TB mortality in Colombia suggest the need to comprehensively address strategies for reducing TB by considering social determinants and including health education strategies throughout the country.
\end{abstract}

Tuberculosis; Mortality; Socioeconomic Factors
Salomé Valencia-Aguirre 1

Ivan Arroyave 2

Alberto L. García-Basteiro 3,4

\author{
Correspondence \\ I. Arroyave \\ Facultad Nacional de Salud Pública, Universidad de Antioquia. \\ Calle 62 52-59, Medellín, Antioquia - 050010474, Colombia. \\ ivan.arroyave@udea.edu.co \\ 1 Observatorio Nacional de Salud, Instituto Nacional de Salud, \\ Bogotá, Colombia. \\ 2 Facultad Nacional de Salud Pública, Universidad de \\ Antioquia, Medellín, Colombia. \\ 3 Centro de Investigação em Saúde de Manhiça, Maputo, \\ Moçambique. \\ 4 Institut de Salut Global de Barcelona, Universitat de \\ Barcelona, Barcelona, España.
}




\section{Introduction}

Tuberculosis (TB) has been a major global health problem throughout human history and has claimed countless victims 1. According to the World Health Organization (WHO), 10 million people were affected by this disease in 2019, with 1.2 million deaths due to TB in HIV-negative people compared to 208,000 among HIV-positive people 2. Colombia was among the countries with the highest number of cases in Latin America in 2018, with 16,000 notified cases (new and relapse) 3. From 2012, there has been a constant increase in the number of cases, from 23.0 cases per 100,000 inhabitants in 2013 to 27.3 cases per 100,000 inhabitants in 20194 .

Individuals with conditions such as HIV or diabetes have a higher risk of acquiring TB and suffering more severe complications ${ }^{5}$. Furthermore, TB has been recognized as a poverty-related disease 6 ; poverty influences access to health care, timely diagnosis, and treatment initiation and outcomes, among others 7 . Thus, the identification of inequalities from the social determinants of health (SDH) approach 8 becomes a fundamental tool in the analysis of health problems ${ }^{9}$, and targeting inequalities should be regarded as a key intervention for TB reduction; this has already been proposed by the Colombian government strategic plan to end TB (2016-2025) 10.

In this framework, education acts as a structural determinant of health, used frequently as an indicator of socioeconomic position 8 . Although the association between education and health is well-known 11, there is no clear explanation for this complex relationship. Four pathways through which education affects health have been identified: economic, behavioral, social-psychological, and access to health services 12 . However, approaches to this phenomenon solely in terms of achievement do not cover aspects that could independently influence health, such as quality or type of education, and contextual factors (cultural, geographic) 9. For example, in Colombia, there has been an increase in educational attainment 13; however, the economic and dwelling inequalities (urban/rural) in access, quality, and school achievement remain the same 14 .

There is a substantial amount of evidence regarding the effect of educational level on the diagnostic and treatment of TB 5,15,16,17,18, emphasizing the need for national programs focused on high-risk groups (migrants, prisoners, alcohol users, HIV-coinfection) 19,20. Also, education is a central component of primary health care (PHC) and a useful strategy for promoting health equity that should be adapted to a wide variety of social, cultural, and economic contexts that involve the new epidemiological challenges, including the achievement of the Sustainable Development Goals (SDGs).

In Colombia, studies have been carried out, showing an association of educational level and delays in diagnostic and tuberculosis relapse in two municipalities of Colombia 21,22. A substantive contribution of this study is that it was carried out at the national level, by age group and sex, over the period of 10 years. Allowing the identification of statistically significant periods. A potential hypothesis is that TB mortality in Colombia affects the lower socioeconomic groups the most, understood as those with lower educational attainment.

We aim to describe the role of educational inequalities for sex and age groups in adult TB mortality in Colombia, 1999-2017.

\section{Materials and methods}

\section{Study design}

To explore the educational inequalities of TB mortality for different adult age groups, an observational ecological study was conducted, using aggregated national data on mortality and official population estimates to calculate the denominators of mortality rates.

Our methods are similar to those used in previous studies 23,24 .

\section{Study setting}

Colombian population-based, national secondary mortality data, 1999-2017. 


\section{Population and data}

Mortality data and population projections (1999-2017) from the official records of the Colombian National Administrative Department of Statistics (DANE) were used 25,26,27, derived from vital registries based on death certificates issued by a physician or authorized health officer. Information was collected on sex, age, and educational level of those whose death were caused by TB and its sequelae (A15-A19, B90), according to the International Classification of Diseases, 10th revision (ICD-10) 28. To ensure that the population involved in the study had achieved their final educational level, the age range selected was adults ( 25 and over), categorized into three age groups: young adults (25-44 years), middle-aged adults (45-64 years), and older adults (65 years and older).

The reported mid-year population data were selected and collected by educational level, in four stages. Firstly, the annual DANE population report, constructed based on the population censuses and the DANE statistical projections, were used. Secondly, surveys on the educational level of the population was obtained from the National Demographic and Health Surveys (DHS) for the years 1995, 2000, 2005, and 2010. The DHS provides information on the distribution of education by five-year age group, sex, and year. Thirdly, the annual population size was obtained for each educational level, multiplying the percentage of individuals in each educational category of the DHS by the population count of the censuses and statistical projections. Finally, to obtain annual population counts, smoothed interpolations were made for the remaining years using the Population Analysis System demographic software (https://www.census.gov/data/software/pas.html). Considering the last year studied, the levels of education were reclassified into three categories: primary, secondary (high school), and tertiary (higher education).

Information on the level of education was absent in 39.4\% of the deaths. Multiple imputations of educational levels were carried out with IVEware software (http://www.isr.umich.edu/src/smp/ive), using demographic variables as predictive variables (sex, 5-year age group, department and municipality of origin, urban/rural provenance, marital status). This imputation was carried out to avoid bias due to potentially higher mortality rates among people with lower educational levels, and to minimize the possibility of a numerator/denominator bias 29,30; to account for the uncertainty of the imputation, the standard error (SE) was estimated.

\section{Data analysis}

Age-standardized mortality rates (ASMR) were estimated and the relative inequalities in mortality and the annual percentage change (APC) were evaluated. The Joinpoint Trend Analysis Software 4.8.0 (https://surveillance.cancer.gov/joinpoint/) was used to calculate the average change in the mortality rate per year over a period of time.

ASMR were estimated by sex, age groups, educational level, and year. The direct standardization method was used with the 1997 WHO standard population as a reference 31.

Relative inequalities in mortality were evaluated by calculating the rate ratio (RR) and the relative index of inequality (RII). The RR compares mortality among all educational groups against the highest educational level assuming that it is the reference value since it has the lowest expected mortality. On the other hand, the RII takes the size of each educational group and the mortality at the midpoint of the cumulative distribution of education ${ }^{29}$, comparing the lowest educational level with the highest. Consequently, an increase in the RII indicates an increase in inequalities in the educational hierarchy. Age and educational level were incorporated as independent variables. The statistical analyses were performed in SAS version 9.4 (https://www.sas.com/).

The APC was used to calculate the average change in the mortality rate per year, over a period of time. When the APC is negative, it indicates a trend towards the reduction of mortality. To verify the statistically significance of this changes, a joinpoint regression was used. This is adjusted to a series of straight lines joined to the rates adjusted for age and uses a Monte Carlo permutation method to identify the best-fit point (called the junction point), where the rate of increase or decrease changes significantly. The joinpoints are determined based on the logarithmic transformation of the mortality rates, their SE, and 95\% confidence intervals (95\%CI), and they are expressed as the average annual percentage change (AAPC). The level of statistical significance used was $\mathrm{p}<0.05$. 


\section{Ethical aspects}

The study was endorsed by the Ethics Committe of the National School of Public Health, University of Antioquia. The study is classified as no risk for being a secondary data analysis.

\section{Results}

In the 1999-2017 period, 19,720 deaths from TB and sequelae were reported in Colombia among people aged over 25 years. Table 1 shows ASMR among the Colombian population (aged over 25) by age and sex, according to educational level. The group aged over 65 years represented almost half of the total deaths $(45 \%, \mathrm{n}=9,006)$. Men had higher ASMR (7.1 deaths/100,000 inhabitants) compared to women (2.7/100,000 inhabitants).

Table 1

Number of deaths by tuberculosis and population, age-standardized mortality rate (ASMR), and rate ratio (RR) in tuberculosis among adult Colombian population (aged over 25 years), calculated for the period (1999-2017), separated by age groups and educational level.

\begin{tabular}{|c|c|c|c|c|c|c|}
\hline Sex/Age group (years) & Educational level * & Deaths ** & Population-year & $\begin{array}{l}\text { ASMR *** } \\
\text { Rate (SE) }\end{array}$ & $\begin{array}{c}\text { APC of ASMR } \\
(95 \% \mathrm{Cl})\end{array}$ & $\mathrm{RR} \#(95 \% \mathrm{Cl})$ \\
\hline \multirow[t]{3}{*}{ Adult men $(25+)$} & Primary & 10,885 & 91,625 & $0.90(0.10)$ & $-1.9(-2.5 ;-1.4)$ & $6.36(6.09 ; 6.54)$ \\
\hline & Secondary & 2,360 & 75,242 & $4.64(0.14)$ & $-3.4(-4.5 ;-2.2)$ & $2.00(2.85 ; 3.16)$ \\
\hline & Terciary & 459 & 44,565 & $1.61(0.10)$ & $-6.4(-8.6 ;-4.1)$ & 1.00 \\
\hline \multirow[t]{3}{*}{ Young (25-44) } & Primary & 1,599 & 36,708 & $4.22(0.11)$ & $-0.6(-1.6 ; 0.5)$ & $9.35(8.57 ; 9.99)$ \\
\hline & Secondary & 829 & 49,310 & $1.72(0.07)$ & $-3.6(-5.1 ;-2.1)$ & $3.95(3.62 ; 4.33)$ \\
\hline & Terciary & 125 & 30,235 & $0.44(0.05)$ & $-9.8(-11.7 ;-7.9)$ & 1.00 \\
\hline \multirow[t]{3}{*}{ Middle-aged (45-64) } & Primary & 3,870 & 35,793 & $10.65(0.18)$ & $-2.7(-3.7 ;-1.6)$ & $5.66(5.45 ; 5.77)$ \\
\hline & Secondary & 965 & 22,214 & $4.56(0.17)$ & $-5.2(-6.9 ;-3.4)$ & $2.58(2.41 ; 2.63)$ \\
\hline & Terciary & 199 & 11,789 & $1.78(0.140$ & $-8.5(-10.6 ;-6.3)$ & 1.00 \\
\hline \multirow[t]{3}{*}{ Senior (65+) } & Primary & 5,416 & 19,124 & $28.32(0.39)$ & $-2.0(-2.7 ;-1.3)$ & $5.07(4.74 ; 5.25)$ \\
\hline & Secondary & 566 & 3,718 & $15.22(0.84)$ & $-2.1(-3.4 ;-0.7)$ & $2.79(2.47 ; 3.02)$ \\
\hline & Terciary & 136 & 2,542 & $5.36(0.54)$ & $-4.0(-7.1 ;-0.9)$ & 1.00 \\
\hline \multirow[t]{3}{*}{ Adult women (25+) } & Primary & 4,822 & 98,167 & $3.98(0.07)$ & $-3.2(-4.0 ;-2.4)$ & $6.99(6.46 ; 7.26)$ \\
\hline & Secondary & 1,008 & 83,948 & $1.54(0.07)$ & $-4.2(-6.2 ;-2.1)$ & $2.76(2.67 ; 2.81)$ \\
\hline & Terciary & 186 & 50,872 & $0.65(0.07)$ & $-9.0(012.7 ;-5.1)$ & 1.00 \\
\hline \multirow[t]{3}{*}{ Young (25-44) } & Primary & 851 & 36,886 & $2.25(0.09)$ & $-1.7(-3.4 ; 0.0)$ & $9.75(8.91 ; 10.57)$ \\
\hline & Secondary & 438 & 51,913 & $0.85(0.05)$ & $-3.2(-4.8 ;-1.6)$ & $3.83(3.69 ; 4.12)$ \\
\hline & Terciary & 74 & 36,068 & $0.21(0.03)$ & $-9.2(-12.9 ;-5.4)$ & 1.00 \\
\hline \multirow[t]{3}{*}{ Middle-aged (45-64) } & Primary & 1,389 & 37,684 & $3.63(0.11)$ & $-3.9(-5.0 ;-2.7)$ & $6.63(6.22 ; 6.99)$ \\
\hline & Secondary & 315 & 26,776 & $1.21(0.09)$ & $-5.0(-7.2 ;-2.8)$ & $2.33(2.27 ; 2.43)$ \\
\hline & Terciary & 61 & 12,801 & $0.51(0.07)$ & $-11.3(-14.6 ;-7.9)$ & 1.00 \\
\hline \multirow[t]{3}{*}{ Senior $(65+)$} & Primary & 2,583 & 23,596 & $10.94(0.22)$ & $-3.5(-4.2 ;-2.8)$ & $4.41(3.98 ; 4.90)$ \\
\hline & Secondary & 5,260 & 5,260 & $4.84(0.35)$ & $-5.6(-6.9 ;-4.3)$ & $1.91(1.77 ; 2.08)$ \\
\hline & Terciary & 51 & 2,003 & $2.55(0.42)$ & $-5.6(-8.7 ;-2.5)$ & 1.00 \\
\hline
\end{tabular}

95\%Cl: 95\% confidence interval; APC: annual percent change; SE: standard error.

* Educational level after the imputation (Primary = primary; Secondary = any secondary level; Tertiary = any level above secondary, including university studies);

** Deaths due to tuberculosis, after imputation;

*** ASMR per 100,000 inhabitants. All estimates (1997 World Health Organization standard population 30) for the educational level combine 5 databases generated by multiple imputations;

\# Were calculated based on Poisson regression models. 
Table 2 shows the relative differences by educational level, age, and sex; in which the less-educated population had a higher ASMR. TB deaths among those with a primary educational level, which were especially high among young adult men, accounted for $80 \%$ (population-year was only $43 \%$ ), compared to those with tertiary studies ( $3 \%$ of TB deaths, $21 \%$ of population-year [RII = 13.9; 95\%CI: 13.3; 14.4] and women RII = 17.0; 95\%CI: 15.1; 19.0).

Figure 1 shows the trends over the studied period in TB mortality rates by sex and age group. The joinpoint analysis identified that all sex and age groups presented a sharp decline in TB mortality throughout the whole period. The analysis identified two periods: between 1999 and 2012 for men and 2011 for women, there was a statistically noticeable decrease in TB mortality rates, with APC = $-4.6 \%$ (95\%CI: $-6.0 ;-3.2)$ for men and APC $=-5.9 \%$ (95\%CI: $-8.0 ;-3,9 \%)$ for women. From that year onwards there were no statistically significant changes in TB mortality (Figure 1). The stagnation in the decrease among adult men could be explained by the change in the slope of the trend among senior men, which is the group with the largest share of TB mortality (Figure 2). The pace of the reduction was consistently higher among those highly educated, particularly among young adults (25-44 years), as shown in Figure 3. The rate of the decline in TB mortality (APC) among the young was 16 times higher for men who achieved tertiary education compared with those with a primary level, while the same relationship among women was 5.4 times (Table 1).

Consequently, inequalities measured by RII grew at a rate (APC) of $11.7 \%$ among young men and $11 \%$ among young women during the period (Table 2). We only found RII to reduce among senior women APC $=-14,5 \%(95 \% \mathrm{CI}:-15,3 ;-12,2)$, which can be observed in the convergence of the TB mortality trends among educational groups in senior women (Figure 3).

\section{Discussion}

From 1999 to 2017, the ASMR among men was 7.1 TB deaths per 100,000 men and among women 2.7 TB deaths per 100,000 women. During the study period there was a decrease in mortality up to 2011, with a subsequent stagnation until 2017. Colombia is not included in the WHO's high TB burden country list 2 . Nevertheless, the current national mortality rate continues to be high and there are wide spatial gaps, with a higher burden in the country's poor areas, and in some cases such as the Colombian Amazon, a high proportion of the indigenous population ${ }^{3}$.

\section{Table 2}

Age-standardized mortality rate (ASMR) and relative index of inequality (RII) in tuberculosis among adult Colombian population (aged over 25 years), calculated for the period (1999-2017) separately by age groups.

\begin{tabular}{|c|c|c|c|c|}
\hline Sex/Age group (years) & $\begin{array}{l}\text { ASMR * } \\
\text { Rate (SE) }\end{array}$ & APC ** of ASMR $(95 \% \mathrm{Cl})$ & $\mathrm{RII} * * *(95 \% \mathrm{Cl})$ & APC of RII $(95 \% \mathrm{Cl})$ \\
\hline Adult men $(25+)$ & $7.13(0.06)$ & $-3.7(-4.3 ;-3.1)$ & $9.68(9.46 ; 9.94)$ & $7.8(7.0 ; 8.2)$ \\
\hline Young (25-44) & $2.22(0.04)$ & $-4.2(-5.2 ;-3.2)$ & $13.93(13.35 ; 14.44)$ & $11.7(10.4 ; 13.4)$ \\
\hline Middle-aged (45-64) & $7.34(0.10)$ & $-4.8(-5.6 ;-4.1)$ & $9.39(9.08 ; 9.59)$ & $10.0(9.3 ; 10.6)$ \\
\hline Senior $(65+)$ & $24.10(0.31)$ & $-2.7(-3.5 ;-1.9)$ & $6.91(6.62 ; 7.14)$ & $3.4(2.4 ; 4.2)$ \\
\hline Adult women (25+) & $2,70(0.03)$ & $-5.0(-5.7 ;-4.4)$ & $13.38(12.03 ; 14.37)$ & $1.0(0.3 ; 1.7)$ \\
\hline Young (25-44) & $1.09(0.03)$ & $-5.8(-6.7 ;-4.9)$ & $16.96(15.06 ; 19.01)$ & $11.0(9.0 ; 12.7)$ \\
\hline Middle-aged (45-64) & $2.32(0.06)$ & $-6.0(-7.2 ;-4.9)$ & $15.59(13.95 ; 17.86)$ & $1.7(1.4 ; 2.3)$ \\
\hline Senior $(65+)$ & $9.36(0.17)$ & $-4.1(-4.8 ;-3.4)$ & $14.16(11.79 ; 15.75)$ & $-14.5(-15.3 ;-12.2)$ \\
\hline
\end{tabular}

95\%Cl: 95\% confidence interval; APC: annual percent change; SE: standard error.

* ASMR per 100,000 inhabitants. All estimates (1997 World Health Organization standard population 30) for the educational level combine 5 databases generated by multiple imputations;

** APC: Joinpoint Trend Analysis Software was used to calculate percentage of change in mortality rate and in RII along the period;

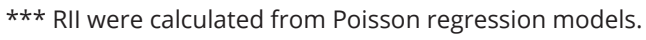


Trends of adult (25+ years) tuberculosis (TB) age-standardized mortality rates (ASMR) separated by sex, including annual percentage change (APC) based on joinpoint models. Colombia, 1999-2017.

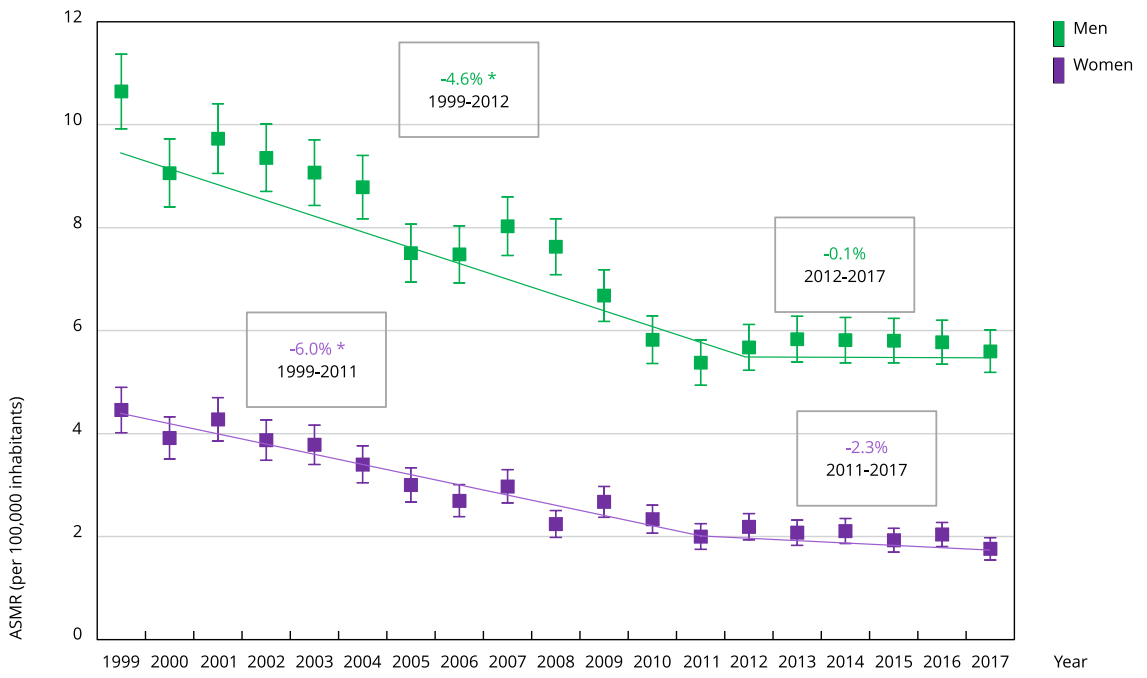

Note: TB mortality rates were standardized by age among adults over 25 years of age. The points represent ASMR, the lines represent the trend lines between points of union. The numbers adjacent to the lines represent the estimates of the APC during the corresponding periods, depending on the joinpoint model.

* Statistical significance at $\alpha=0.05$.

We found that TB mortality was 2.6 times higher in men than in women, corroborating a previous report 5. A systematic review and meta-analysis on sex differences in tuberculosis burden and notifications found that, in many settings, men may be less likely to seek or access care or to have a prompt diagnosis, thus, having more secondary infections compared to women 32 . By age, people aged over 65 years had the highest ASMR, and, for both sexes, there was a gradient of higher ASMR as the age increases. The higher mortality among older adults has been explained by the weakness of their immune system due to comorbidities, difficulties in diagnosis because of uncommon symptoms, and their higher risk to develop more severe and atypical forms of TB 33 .

We found TB mortality inequalities to be especially higher if compared with other causes of death we previously analyzed 23,34,35. A broad study comparing 16 European countries found that adult (3579 years) RII was greater in Eastern European and Baltic countries (those less favored, and with higher TB mortality rates), but relatively small in those more developed and egalitarian countries: Scandinavia (except Denmark) and Southern Europe 16. For instance, they found Hungary to have a TB mortality of 5.8/100,000 inhabitants (7.6 among the lower educated and 2.5 for the higher educated), and RII $=16.4$ (95\%CI: $12.1 ; 22.2)$ 16. They hypothesize unfavorable social conditions and comorbidities (in particular HIV, which was, at the time, the most significant confounder) to be potentially associated with both higher mortality and inequalities in some countries. Other study-comparing inequalities trends in TB mortality, in 11 countries from different regions of Europe 15, found that inequalities mostly reduced with time, which is contrary to our findings; except for older women, among whom we found a striking reduction in RII. Education as an indicator of healthcare-seeking behavior was also analyzed in countries with a high incidence of TB - such as Pakistan, Bangladesh, and Uganda - and showed that at a higher educational level, there was a greater awareness of care in patients and a greater knowledge about TB infection regarding means of infection, prevention, and treatment $36,37,38$. 


\section{Figure 2}

Trends of adult (25+ years) tuberculosis (TB) age-standardized mortality rates (ASMR) separated by sex and age group, including annual percentage change (APC) based on joinpoint models. Colombia, 1998-2015.

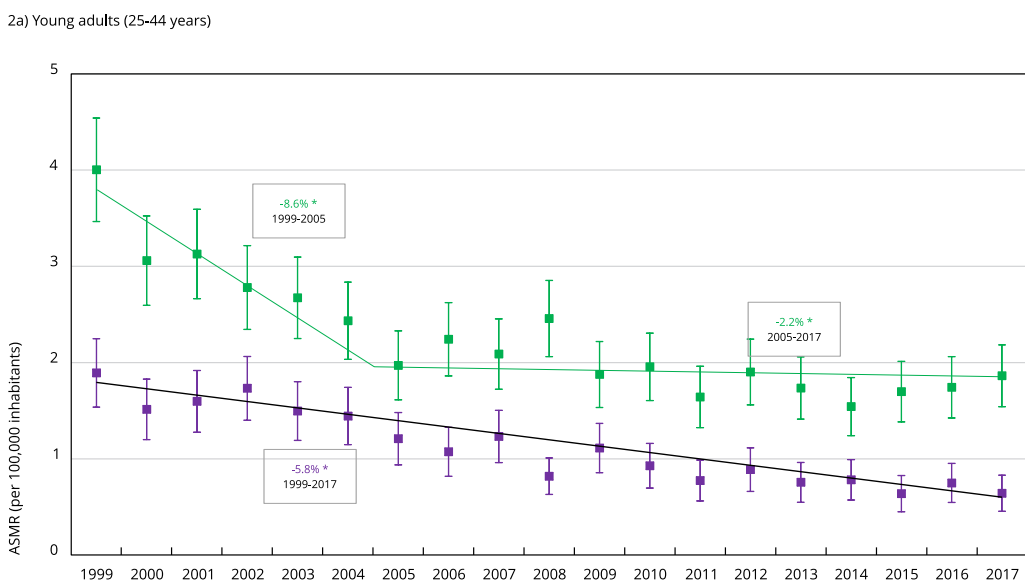

2b) Middle-aged adults (45-64 years)

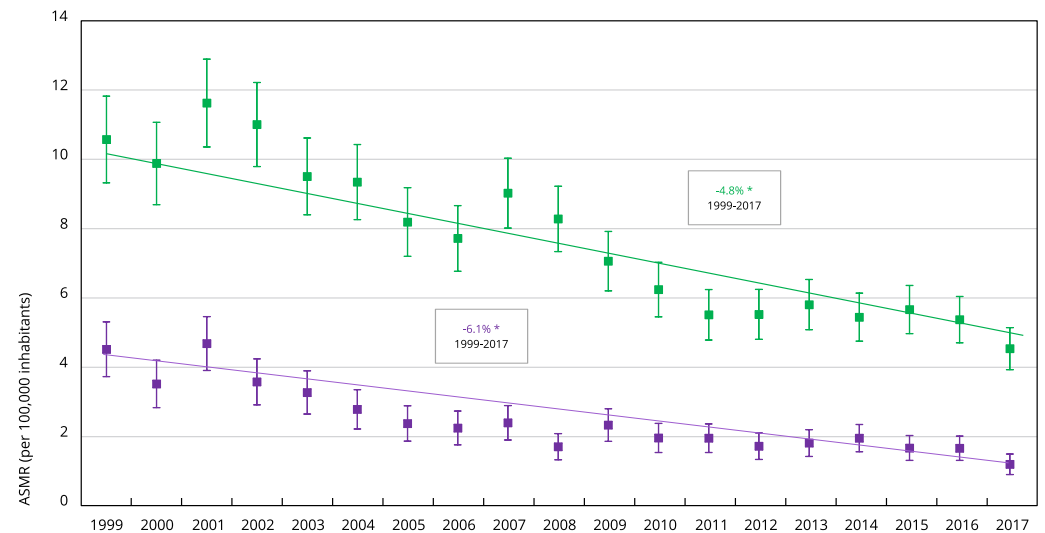

2c) Senior adults (65+ years)

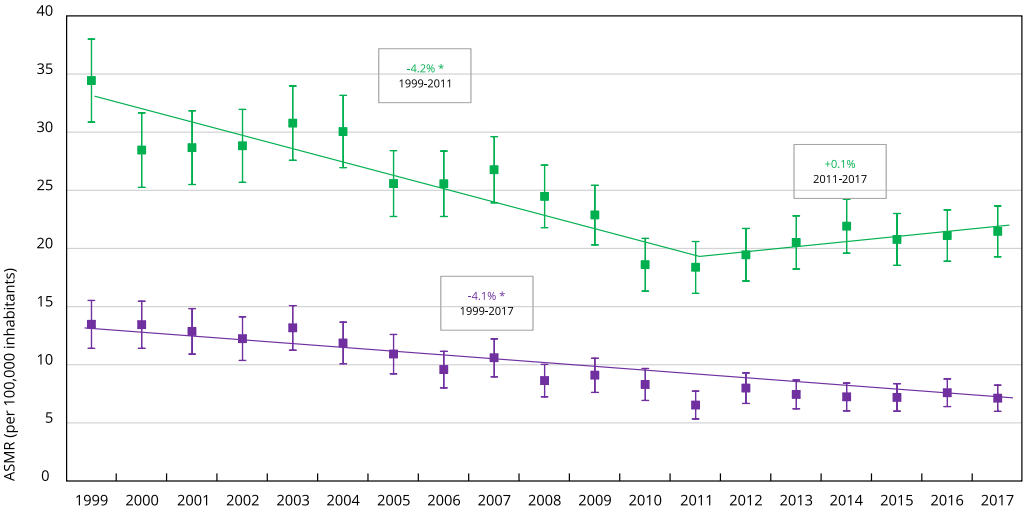


Figure 3

Trends of adult (25+ years) tuberculosis (TB) age-standardized mortality rates (ASMR) by sex, age group, and educational level, including annual percentage change (APC) based on joinpoint models, by age group and educational level. Colombia, 1998-2015.
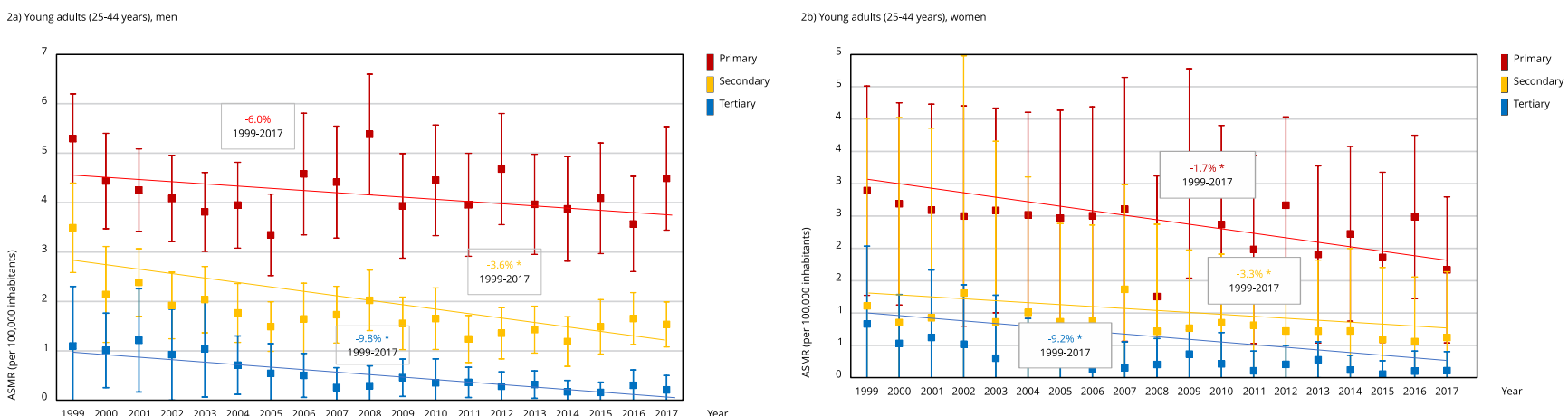

2c) Middle-aged adults (45-64 years), men
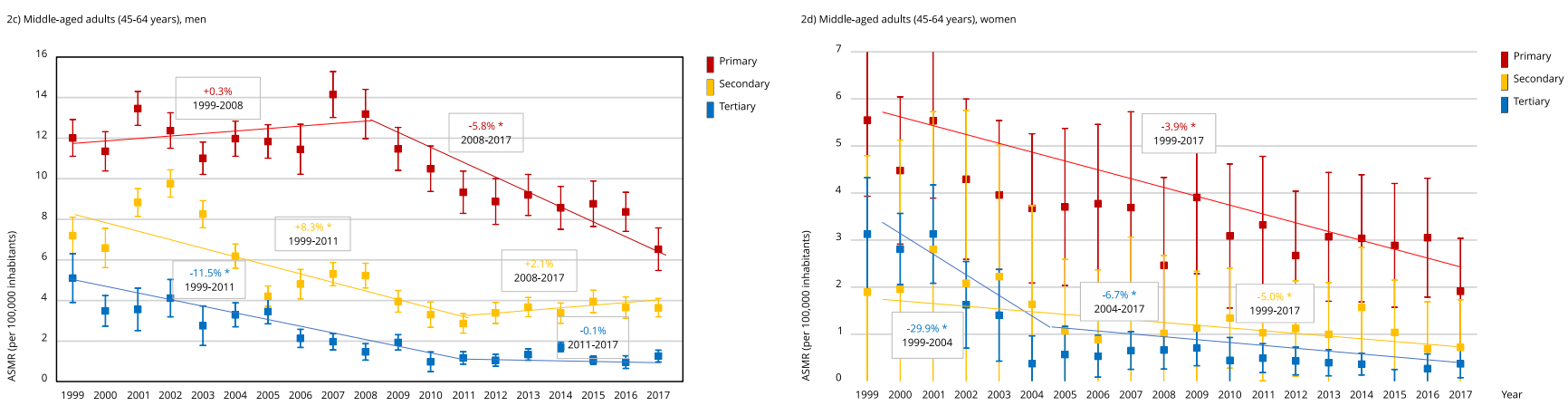

2e) Senior adults (65+ years), men

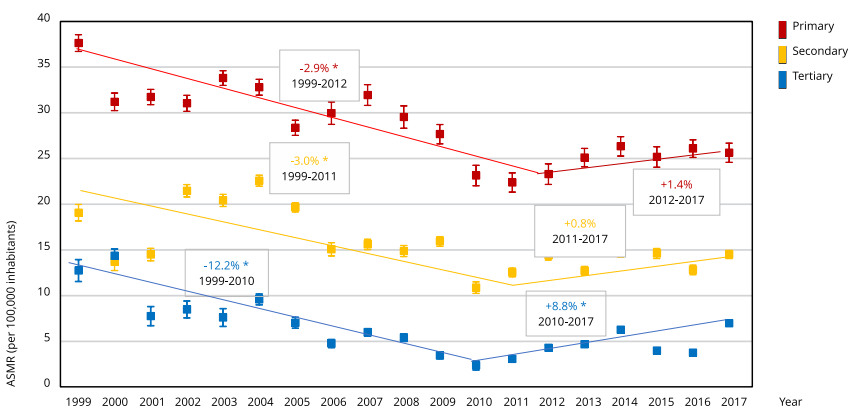

$2 \uparrow$ Senior adults (65+ years), women

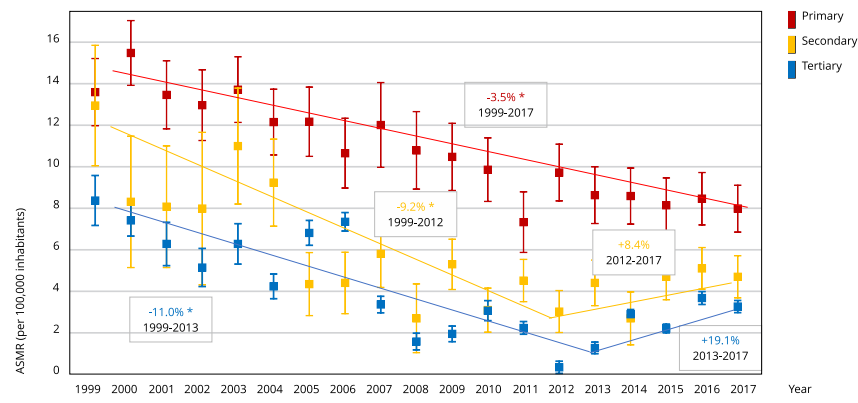

Note: TB mortality rates were standardized by age among adults over 25 years of age. The points represent ASMR, the lines represent the trend lines between points of union. The numbers adjacent to the lines represent the estimates of the annual percentage change (APC) during the corresponding periods, depending on the joinpoint model.

* Statistical significance at $a=0.05$.

Even though men had higher mortality, educational inequalities were notoriously higher for women: RII/men = 9.7 (95\%CI: 9.5; 9.9) and RII/women = 13.4 (95\%CI: 12.0; 4.4). Gender-related differences act as a proximal determinant that responds to social norms, roles, and status, and also interacts with other determinants. Krishnan et al. 39 identified that women face several barriers, such as lack of financial and physical independence, low general and TB-related literacy, and stigma within the household. Larger inequalities were also found among the younger population group although we did not identify explanations for this finding in other similar studies. This result may be associated with the relevance that educational level has gained in recent decades, as one of the main mechanisms 
to have social security, employment, and social success 9 . Therefore, the pronounced educational inequalities in Colombia (public/private education, rural/urban) 40,41, which lead to a lack of opportunities and economic disparities, may have larger consequences among the younger group of study (25-44 years old) which is also the economically active population.

When analyzing the behavior of inequities over time, we found that the APC decrease in ASMR was much higher among those with higher education, for both sexes and in all age groups, leading to a noticeable growth of inequalities (APC of RII); except for older women, in which inequality decreased during the period and an increase in ASMR among those with higher education.

ASMRs were higher in primary and secondary educational levels compared to the highest level of education (tertiary), for both sexes and in all age groups (Table 1).

Although TB mortality decreased for both sexes during the study period, the joinpoint regression showed a statistically significant decrease of the ASMR between 1999 and 2012/2011 among men and women, respectively, with a subsequent stagnation for both sexes. The first period of reduction may reflect the efforts of national programs to improve the availability of effective chemotherapy and diagnosis 42 . The explanation for this does not seem to be related to the strategies adopted to achieve the Millennium Development Goals (MDGs). On the other hand, these inequalities may also be mediated by the structural characteristics of the health system in Colombia, which underwent significant changes after the implementation of Law 100/1993, a reform that moved from a National Health System (financed by taxes and revenues and controlled by the Colombian Ministry of Health) to a privatized resource managed by insurers 42; that increased the coverage of the affiliation to the General System of Social Security in Health (SGSSS), but segmented the quality of the services according to income 43 .

Moreover, tuberculosis among the vulnerable and at-risk populations continues to be above national estimates, the number of patients with multidrug-resistant TB has increased, barriers to access to healthcare remain, and subnational differences continue to be very wide 44 .

\section{Potential limitations}

As with previous study using this approach 23 , we found that, despite several strengths, some limitations should be considered in our study. Data on mortality were obtained from mortality registries, while data on the population distribution by education were obtained from censuses and demographic projections. This may have led to the so-called numerator/denominator bias, which generally results in an overestimation of disparities 45. Furthermore, for some years, data on population size were obtained from demographic projections combined with distributions of education from surveys. To assess the impact of this potential bias, we experimented with different education distributions from multiple data sources 46,47 and found them to be almost identical, which gives us confidence in the distribution used in the study 48 . Additionally, the variable of educational level does not fully explain the health knowledge of individuals and does not fully predict TB-related health outcomes. Furthermore, our methodological approach does not allow us to determine the degree of health education or the impact of the educational level on it.

Possibly, there has been substantial under-registration of deaths in some regions. Previous studies 49,50 comparing national mortality rates with indirect estimates from census suggest that underregistration is particularly significant in the poorest regions (such as Pacific and Colombian Amazon), implying that estimates of disparities in mortality by educational level are likely to be an underestimation, since those with lower education are more likely to live in areas with higher under-registration rates. This may also have led to an underestimation of the extent to which inequalities have increased, since under-registration has decreased over the study period 49,50. Our results, therefore, are indicative of potentially larger inequalities in mortality by education, which continues to increase.

Information on education was missing for $35.3 \%$ of the reported deaths, potentially leading to an underestimation of disparities, since missing values are usually more common in the least educated 51,52 . However, we imputed values for educational level for individuals with missing educational information based on a potentially high predictive set of variables, and used multiple imputations, thereby limiting the potential impact of this source of bias. 


\section{Conclusions}

Colombia faces the double challenge of having relatively high TB mortality, as well as high and growing inequalities. This corroborates the need to continue including the social determinants of health in all the strategies that are implemented, which should contribute to a downward trend in mortality by tuberculosis. To better understand our results for inequalities in TB mortality in Colombia, it would be necessary to disentangle how the social distribution of TB risk factors and comorbidities, especially, with HIV, are confounding our results. Note that, other factors potentially contributed to inequalities, such as the rural/urban distribution of TB, distribution among the indigenous populations, or by deepening the effects of the prolonged armed conflict that the country has experienced for more than 50 years.

These and other findings would shed light on how stakeholders could better address this endeavor and effectively focus on strategies, contributing to lessening both mortality and inequalities (as well as lethality) of TB in Colombia. This entails not only a joint and intersectoral effort that guarantees access to higher-quality education but also the use of useful models of care in promoting health education in the territories and groups with the most vulnerable populations. Unfortunately, we could not address the effects of health education in this study.

Additionally, the implications for health professionals include not only training health personnel in charge of primary health care but also communicating adequately with patients to improve health behaviors, adherence, and treatment outcomes.

High and growing inequalities in Colombia result in a double challenge that urgently needs to be addressed. We cannot discard the stagnation in the recent reduction of TB mortality as being at least partially due to the ineffectiveness in reducing inequalities among those less favored.

\section{Contributors}

S. Valencia-Aguirre and A. L. García-Basteiro contributed to the writing and critical review of the manuscript. I. Arroyave contributed to the study conception and design and data analisis and interpretation. All authors are responsible for all aspects of the work to ensure the accuracy and integrity of any part of the work and approved the final version to be published.

\section{Additional informations}

ORCID: Salomé Valencia-Aguirre (0000-00025285-410X); Ivan Arroyave (0000-0001-99895833); Alberto L. García-Basteiro (0000-00022038-5505).

\section{Conflict of interests}

This research received no specific grant from any funding agency in public, commercial or not-forprofit sectors. There is no financial support for this work that could have influenced its outcome. 


\section{References}

1. Paulson T. Epidemiology: a mortal foe. Nature 2013; 502:S2-3.

2. World Health Organization. Global tuberculosis report 2020. Geneva: World Health Organization; 2020.

3. Pan American Health Organization. Tuberculosis in the Americas, 2018. http://iris.paho. org/xmlui/handle/10665.2/49510 (accessed on 08/Jun/2020).

4. Instituto Nacional de Salud. Boletín epidemiológico semanal 2020; (11).

5. Duarte R, Lönnroth K, Carvalho C, Lima F, Carvalho ACC, Muñoz-Torrico M, et al. Tuberculosis, social determinants and co-morbidities (including HIV). Pulmonology 2018; 24:115-9.

6. Saunders MJ, Evans CA. Fighting poverty to prevent tuberculosis. Lancet Infect Dis 2016; 16:395-6.

7. Erlinger S, Stracker N, Hanrahan C, Nonyane S, Mmolawa L, Tampi R, et al. Tuberculosis patients with higher levels of poverty face equal or greater costs of illness. Int J Tuberc Lung Dis 2019; 23:1205-12.

8. World Health Organization. A conceptual framework for action on the social determinants of health. https://apps.who.int/iris/han dle/10665/44489 (accessed on 27/Jun/2020).

9. Zajacova A, Lawrence EM. The relationship between education and health: reducing disparities through a contextual approach. Annu Rev Public Health 2018; 39:273-89.

10. Ministerio de Salud y Protección Social. Plan estrategico: "Hacia el fin de la tuberculosis, 2016-2025”. Bogotá: Ministerio de Salud y Protección Social; 2016

11. Hamad R, Elser H, Tran DC, Rehkopf DH, Goodman SN. How and why studies disagree about the effects of education on health: a systematic review and meta-analysis of studies of compulsory schooling laws. Soc Sci Med 2018; 212:168-78.

12. Raghupathi V, Raghupathi W. The influence of education on health: an empirical assessment of OECD countries for the period 1995-2015. Arch Public Health 2020; 78:20.

13. The World Bank. Education statistics: education attainment. https://databank.worldbank. org/source/education-statistics:-EducationAttainment (accessed on 05/Feb/2020).

14. Gaviria S. Plan nacional de desarrollo 20142018. Bogotá: Departamento Nacional de Planeación; 2014.

15. Nagavci BL, de Gelder R, Martikainen P, Deboosere P, Bopp M, Rychtaříková J, et al. Inequalities in tuberculosis mortality: long-term trends in 11 European countries. Int J Tuberc Lung Dis 2016; 20:574-81.

16. Álvarez JL, Kunst AE, Leinsalu M, Bopp M, Strand BH, Menvielle G, et al. Educational inequalities in tuberculosis mortality in sixteen European populations. Int J Tuberc Lung Dis 2011; 15:1461-7.
17. Pedrazzoli D, Boccia D, Dodd PJ, Lönnroth K, Dowdy DW, Siroka A, et al. Modelling the social and structural determinants of tuberculosis: opportunities and challenges. Int J Tuberc Lung Dis 2017; 21:957-64.

18. Tok PSK, Liew SM, Wong LP, Razali A, Longanathan T, Chinna K, et al. Determinants of unsuccessful treatment outcomes and mortality among tuberculosis patients in Malaysia: a registry-based cohort study. PLoS One 2020; 15:e0231986.

19. de Vries SG, Cremers AL, Heuvelings CC, Greve PF, Visser BJ, Bélard S, et al. Barriers and facilitators to the uptake of tuberculosis diagnostic and treatment services by hardto-reach populations in countries of low and medium tuberculosis incidence: a systematic review of qualitative literature. Lancet Infect Dis 2017; 17:e128-43.

20. Ranzani OT, Rodrigues LC, Bombarda S, Minto CM, Waldman EA, Carvalho CRR. Longterm survival and cause-specific mortality of patients newly diagnosed with tuberculosis in São Paulo state, Brazil, 2010-15: a populationbased, longitudinal study. Lancet Infect Dis 2020; 20:123-32.

21. Córdoba C, Buriticá PA, Pacheco R, Mancilla A, Valderrama-Aguirre A, Bergonzoli G. Risk factors associated with pulmonary tuberculosis relapses in Cali, Colombia. Biomédica (Bogotá) 2020; 40 Suppl 1:102-12.

22. Rodríguez-Márquez I, Montes F, Upegui LD, Montoya N, Vargas NE, Rojas A, et al. Delays in diagnosing pulmonary tuberculosis within a context of medium incidence, Medellín, Colombia, 2017: an operational research. BMC Public Health 2020; 20:757.

23. de Vries E, Arroyave I, Pardo C. Time trends in educational inequalities in cancer mortality in Colombia, 1998-2012. BMJ Open 2016; 6:e008985.

24. Alvis-Zakzuk NJ, Arroyave I, Castañeda-Orjuela C, De La Hoz-Restrepo F, Alvis-Guzman N. Education and pneumonia mortality: a trend analysis of its inequalities in Colombian adults. BMJ Open Respir Res 2020; 7:e000695.

25. Departamento Administrativo Nacional de Estadística. Estadísticas vitales - Bogotá [bases de datos economicas y demograficas]. http:// www.dane.gov.co (accessed on 09/Feb/2020).

26. Gómez CM, Valenzuela MF, Plata JOR. Colombia: proyecciones anuales de población por sexo y edad, 1985-2020. Bogotá: Departamento Administrativo Nacional de Estadística; 1998.

27. Departamento Administrativo Nacional de Estadística. Base de datos de mortalidad. 19852017. Bogotá: Departamento Administrativo Nacional de Estadística; 2018.

28. World Health Organization. International Classification of Diseases (ICD-10). Geneva: World Health Organization; 2010. 
29. Mackenbach JP, Kunst AE. Measuring the magnitude of socio-economic inequalities in health: an overview of available measures illustrated with two examples from Europe. Soc Sci Med 1997; 44:757-71.

30. Kunst AE, Bos V, Andersen O, Cardano M, Costa G, Harding S, et al. Monitoring of trends in socioeconomic inequalities in mortality: experiences from a European project. Demogr Res 2004; Special Collection 2:229-54.

31. Ahmad OB, Boschi-Pinto C, Lopez AD, Murray $\mathrm{CJ}$, Lozano $\mathrm{R}$, Inoue $\mathrm{M}$. Age standardization of rates: a new WHO standard. Geneva: World Health Organization; 2001.

32. Horton KC, MacPherson P, Houben RM, White RG, Corbett EL. Sex differences in tuberculosis burden and notifications in lowand middle-income countries: a systematic review and meta-analysis. PLoS Med 2016; 13:e1002119.

33. Negin J, Abimbola S, Marais BJ. Tuberculosis among older adults: time to take notice. Int J Infect Dis 2015; 32:135-7.

34. Arroyave I, Cardona D, Burdorf A, Avendaño M. Socioeconomic inequalities in premature mortality in Colombia, 1998-2007: the double burden of non-communicable diseases and injuries. Prev Med 2014; 64:41-7.

35. de Vries E, Arroyave I, Pardo C. Re-emergence of educational inequalities in cervical cancer mortality, Colombia 1998-2015. J Cancer Policy $2018 ; 15: 37-44$.

36. Miandad M, Nawaz-ul-Huda S, Burke F, Hamza S, Azam M. Educational status and awareness among tuberculosis patients of Karachi. J Pak Med Assoc 2016; 66:265-9.

37. Mondal M, Nazrul HM, Chowdhury M, Howard J. Socio-demographic factors affecting knowledge level of tuberculosis patients in Rajshahi City, Bangladesh. Afr Health Sci 2014; 14:855-65.

38. Obuku EA, Meynell C, Kiboss-Kyeyune J, Blankley S, Atuhairwe C, Nabankema E, et al. Socio-demographic determinants and prevalence of tuberculosis knowledge in three slum populations of Uganda. BMC Public Health 2012; $12: 536$

39. Krishnan L, Akande T, Shankar AV, McIntire KN, Gounder CR, Gupta A, et al. Gender-related barriers and delays in accessing tuberculosis diagnostic and treatment services: a systematic review of qualitative studies. Tuberc Res Treat 2014; 2014:215059.

40. López Á, Virgüez A, Silva C, Sarmiento J. Desigualdad de oportunidades en el sistema de educación pública en Bogotá, Colombia. Lecturas de Economía 2017; (87):165-90.

41. Huang H, Sebastian J. The role of schools in bridging within-school achievement gaps based on socioeconomic status: a cross-national comparative study. Compare 2015; 45:501-25.
42. Fontalvo-Rivera D, Gómez-Camargo D, Gómez-Arias R. Análisis de la política para el control de la tuberculosis en Colombia. Rev Peru Med Exp Salud Pública 2014; 31:775-80.

43. Yepes FJ, Ramírez M, Sánchez LH, Ramírez ML, Jaramillo I. Luces y sombras de la reforma de la salud en Colombia. Bogotá: Centro Internacional de Investigaciones para el Desarrollo; 2010.

44. Robledo J. Multi-drug resistant tuberculosis: a reachable objective. Biomédica (Bogotá) 2019; 39:431-3.

45. Kunst AE, Groenhof F, Borgan J, Costa G, Desplanques G, Faggiano F, et al. Socio-economic inequalities in mortality. Methodological problems illustrated with three examples from Europe. Rev Epidemiol Sante Publique 1998; 46:467-79.

46. World Population Program, International Institute for Applied Systems Analysis; Vienna Institute of Demography. Education forward projections for 2000-2050. https://iiasa.ac.at/ web/home/research/researchPrograms/ WorldPopulation/Research/ForecastsPro jections/DemographyGlobalHumanCapital/ EducationReconstructionProjections/educa tion_reconstruction_and_projections.html (accessed on 05/Feb/2020).

47. World Bank. World development indicators (WDI). http://data.worldbank.org/data-cata log/world-development-indicators (accessed on $05 / \mathrm{Feb} / 2020$ ).

48. Barro RJ, Lee J-W. A new data set of educational attainment in the world, 1950-2010. Cambridge: National Bureau of Economic Research; 2010.

49. de Vries E, Arroyave I, Pardo EC, Wiesner C, Murillo R, Forman D, et al. Trends in inequalities in premature cancer mortality by educational level in Colombia, 1998-2007. J Epidemiol Community Health 2015; 69:408-15.

50. Patiño-Villada FA, Arango-Vélez EF, Quintero-Velásquez MA, Arenas-Sosa MM. Factores de riesgo cardiovascular en una población urbana de Colombia. Rev Salud Pública 2011; 13:433-45

51. Storr CL, Cheng H, Posada-Villa J, AguilarGaxiola S, Anthony JC. Adult smokers in Colombia: who isn't giving it up? Addict Behav 2008; 33:412-21.

52. Rodríguez-García J. Desigualdades socioeconómicas entre departmentos y su asociación con indicadores de mortalidad en Colombia en 2000. Rev Panam Salud Pública 2007; 21:111-24. 


\section{Resumen}

Pretendemos describir el papel de las inequidades educacionales, según sexo y grupos de edad, en la mortalidad de adultos por tuberculosis (TB) en Colombia, 1999-2017. Relacionamos datos de mortalidad con la estimación de datos de la población nacional, basada en censos y encuestas, con el fin de obtener las tasas de mortalidad primarias, secundarias, $y$ terciarias de adultos (25+ años) estandarizadas por edad, según el nivel educativo. Se realizó un estudio basado en población, usando datos de mortalidad nacional secundaria entre 1999 y 2017. Las tasas de mortalidad por tuberculosis estandarizadas por edad (ASMR), fueron calculadas separadamente por nivel educacional, sexo, y grupos de edad, usando modelos de regresión de Poisson. Las inequidades educacionales relacionadas con la mortalidad en adultos fueron evaluadas calculando el cociente de tasas, y el indice de inequidad relacionado (RII). Se evaluaron tendencias y joinpoints mediante la variación porcentual anual (APC). Se descubrió que, de las 19.720 muertes informadas por TB, un $69 \%$ se produjeron en hombres, $y$ un 45\% en hombres y mujeres adultos mayores (65+). Los hombres presentaron tasas de mortalidad más altas por TB que las mujeres (ASMR hombres = 7,1/100.000 habitantes, ASMR mujeres $=2,7 / 100.000$ habitantes). Asimismo, la mortalidad fue consistentemente más alta en los niveles educacionales más bajos y ambos sexos, además en todos los grupos de edad existieron inequidades altas en la mortalidad por $T B(R I I=9,7$ y 13, 4 entre hombres y mujeres, respectivamente) y creciendo a una tasa anual de un $8 \%$ y $1 \%$. Las altas y crecientes inequidades por nivel educacional en la mortalidad por TB en Colombia apuntan la necesidad de dirigir estrategias que reduzcan la TB ampliamente, tomando en consideración determinantes sociales e incluyendo estrategias de educación en salud en todo el país.

Tuberculosis; Mortalidad; Factores

Socioeconómicos

\section{Resumo}

O estudo tem como objetivo descrever o papel das desigualdades educacionais por gênero e grupo etário na mortalidade por tuberculose (TB) em adultos colombianos entre 1999 e 2017. Relacionamos os dados de mortalidade com as estimativas da população nacional, com base nos censos demográficos e inquéritos para obter as taxas de mortalidade padronizadas por idade (TMPI), primárias, secundárias e terciárias, em adultos com 25 anos ou mais, de acordo com o nivel de escolaridade. Foi realizado um estudo populacional com o uso de dados de mortalidade secundários entre 1999 e 2017. Foram utilizados modelos de regressão Poisson para calcular separadamente as taxas de mortalidade por tuberculose padronizadas por idade, de acordo com o nível de escolaridade, sexo e grupo etário. As desigualdades educacionais relativas na mortalidade em adultos foram avaliadas pelo cálculo da razão de taxas e o índice relativo de desigualdade (IRD). Foram avaliadas as tendências e os joinpoints através da mudança percentual anual média (APC). Entre os 19.720 óbitos por TB notificados, 69\% ocorreram em homens e 45\% em homens e mulheres adultos (65+). Os homens apresentaram taxas de mortalidade por TB maiores que as mulheres (TMPI masculina $=7,1 / 100.000$ habitantes, TMPI feminina $=2,7 / 100.000$ habitantes). A mortalidade era mais alta no nível mais baixo de escolaridade em ambos os sexos e em todos os grupos etários, portanto, as desigualdades na mortalidade por TB eram altas (IRD $=9,7 e$ 13,4 em homens e mulheres, respectivamente), com crescimento anual de $8 \%$ e 1\%. As desigualdades altas e crescentes na mortalidade por TB de acordo com o nível de escolaridade na Colômbia sugerem a necessidade de adotar estratégias abrangentes para reduzir a carga da tuberculose, levando em conta os determinantes sociais e incluindo estratégias nacionais de educação em saúde.

Tuberculose; Mortalidade; Fatores

Socioeconômicos
Submitted on $14 / \mathrm{Feb} / 2021$

Final version resubmitted on $06 / \mathrm{Jul} / 2021$

Approved on 16/Jul/2021 